\title{
Effect of Water on Some Mechanical Properties for Gravel Particles/Polyester Composites
}

\author{
Abbas Fadhil Essa, Ahmed Jadah and Najlaa Jerjack \\ Department of Physics, College of Science, University of Wasit.
}

\begin{abstract}
In view of the developments of industrial applications, this happened in recent years and the need to use composite materials in general and polymer composite especially in the various industrial applications developed. This research deals with the study of the effect of water on some mechanical properties of polymer composite and its matrix material is unsaturated polyester (UPE) reinforced by gravel particles (different types) with particles size of $(I Y,, V \leqslant \mathrm{~nm}$ ) for type (I) and $(1 \cdots, 17 \mathrm{~nm}$ ) for type (II) as a fillers with different weight percentages $(1 \cdot, r \cdot, r \cdot, \varepsilon \cdot) \%$ to prepare polyester composites. The molding method was used to prepare polyester and its composites sheets. The mechanical properties were studied including flexural strength and Young's modulus for the samples at normal conditions (N.C). unsaturated polyester and its composite samples were immersed in water for about $r$. days to find the effect of water on their flexural strength and Young's modulus after immersion (A.I).

The results showed that the samples of UPE / gravels particles type II composite gained highest values of flexural strength $(11 \cdot, 9 \mathrm{MPa})$ as compared with other composites at (N.C) and showed that the samples of UPE / gravels particles type I composite gained highest values of Young's modulus ( $7, \leqslant 9 \mathrm{GPa}$ ) as compared with other composites at (N.C).

Finally, The results showed decrease in values of Young's modulus for all the samples after immersion (A.I) as compared with the samples at (N.C) and showed decrease in values of flexural strength for all the samples except for the composite material of UPE / gravels particles type I at weight percent $(l \cdot, r \cdot) \%$ which showed an increase in the value of flexural strength after immersion (A.I).
\end{abstract}

Keywords: Gravel Particles, Unsaturated Polyester Resin, and Composite Materials.

\section{Introduction}

Composite materials can include fillers of various sizes. In engineering such microcomposite materials are of the greatest importance, the maximum cross size of which usually does not exceed $1 \cdot \mu \mathrm{m}$. Concentration is generally considered to be one of substantial parameters influencing the whole composite properties. [']

Polymer matrix composite materials are considered as modern materials in most of engineering and technical applications.

Particulate reinforced composites constitute

a large portion of these new advanced materials. Thermosetting resins modified with inorganic particles such as carbon, $\mathrm{TiO}, \mathrm{SiO}$, $\mathrm{Al}_{\mathrm{rO}}$, clay. For inorganic/organic composites, the size of particles and the interfacial adhesion have great effect on the properties of the resin matrix $[r, r]$.

Aggregate is the component of composite material that resists compressive stress and provides bulk to the composite material. For efficient filling, aggregate should be much smaller than the finished item, but have a wide variety of sizes. For example, the particles of stone used to make concrete typically include both sand and gravel [ $\varepsilon$ ].

Composites typically use thermoset resins which, begin as liquid polymers and are converted to solids during the molding process. This process, known as cross linking, so that the composite materials have chemical resistance, higher mechanical properties and greater structural durability than thermoplastics. $\left[{ }^{0}\right]$

Young and Beaumont [־], Balqees, Khalid, and Adnan [ $\left.{ }^{\vee}\right]$, Sewench and Najlaa [^], Hanaa [9] and Wasan [1·] studied silica powder, wood flour and rice husk, coconut shell particulates, zinc oxide\& Aluminum oxide and particles of glass based composite respectively. 
The aim of this work is to:- prepare of UPE / gravel composites, produce a composite material of good mechanical properties and suitable for different environmental effects, and evaluation of mechanical properties of the composites such as flexural strength and Young's modulus.

\section{Materials and Methods}

\section{(A) Raw Materials}

The materials used to prepare the composites are unsaturated polyester resin (UPE) type $\left(\mathrm{A}^{-}{ }^{\circ}\right)$ with the hardener Methyl Ethyl Ketone Peroxide (MEKP) and with accelerator cobalt naphthenate (having a symbol SIROPOL) which was supplied from Saudi industrial resin CO. LTD, and two different types of gravel particles were used in this research as follow:
1- Gravel particles type I (take from badra quarry/ Wasit-Iraq) with particles size of $(I Y, V \leq \mathrm{nm}$ ) was used in this work as a filler materials shown in Fig. ( $(-a)$.

$\checkmark$ - Gravel particles-type II (take from Ali Alghrbi quarry/ Misan-Iraq) with particles size of $(1, \cdot, 17 \mathrm{~nm})$ was used in this work as a filler materials shown in Fig. ( $\-b)$.

Measured the chemical composition of these materials using Atomic Absorption Laboratory Ibn Sina actually at Baghdad University College of Science for Girls was the inclusion of the data in the Table (1). And the CSPM Imager Surface Roughness Analysis of gravel particles (GPI and GPII) shown in Fig. $(r)$ and $(r)$.

Table (')

Chemical composition for gravel particles (type I and type II).

\begin{tabular}{|c|c|c|c|c|c|c|c|c|c|c|}
\hline \multirow{2}{*}{$\begin{array}{l}\text { Type of } \\
\text { Gravel } \\
\end{array}$} & \multicolumn{10}{|c|}{ Components } \\
\hline & SiOr & $A l O_{r}$ & Fer & $\mathrm{CaO}$ & $\mathrm{MgO}$ & $\mathrm{Na} \mathrm{O}$ & $\mathrm{K}, \mathrm{O}$ & $\mathrm{MnO}$ & $\mathrm{Pbr}$ & $\mathrm{Cu} \mathrm{O}$ \\
\hline Type I & $r q, \cdot \%$ & -,$\mu r \%$ & $7,97 \%$ & $r T, Y \leq \%$ & $1,91 \%$ & $\cdot, \leqslant \leqslant \%$ & -,$\leqslant 9 \%$ & $\cdot, 11 \%$ & $\cdot, \cdot 1 \wedge \%$ & $\cdot, \cdots \leqslant \%$ \\
\hline Type II & $\cdot, 97 \%$ & $\cdot, 1 \leq \%$ & $r, 17 \%$ & or, TV\% & $\cdot, \wedge \leqslant \%$ &,$+ \cdots 7 \%$ &,$+ \cdots 7 \%$ &., $.19 \%$ &., $.1 r \%$ & - \\
\hline
\end{tabular}

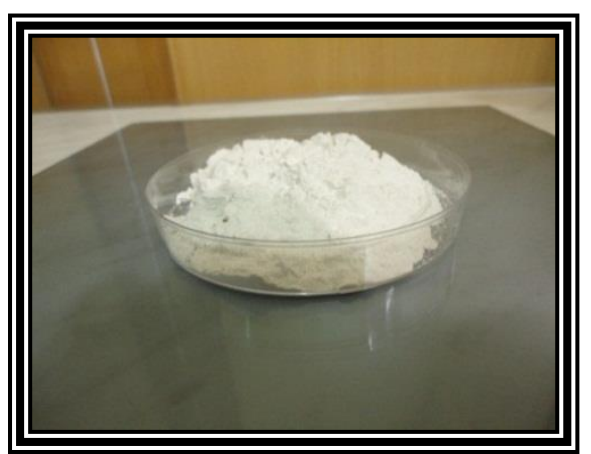

(a)

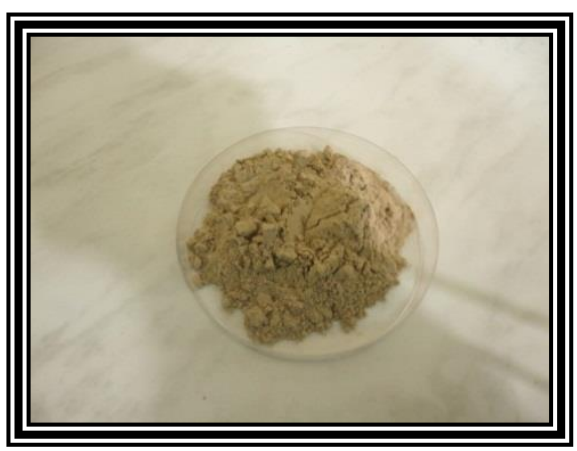

(b)

Fig. ( ') (a) Photograph shows gravel particles type I. (b) Photograph shows gravel particles type II. 

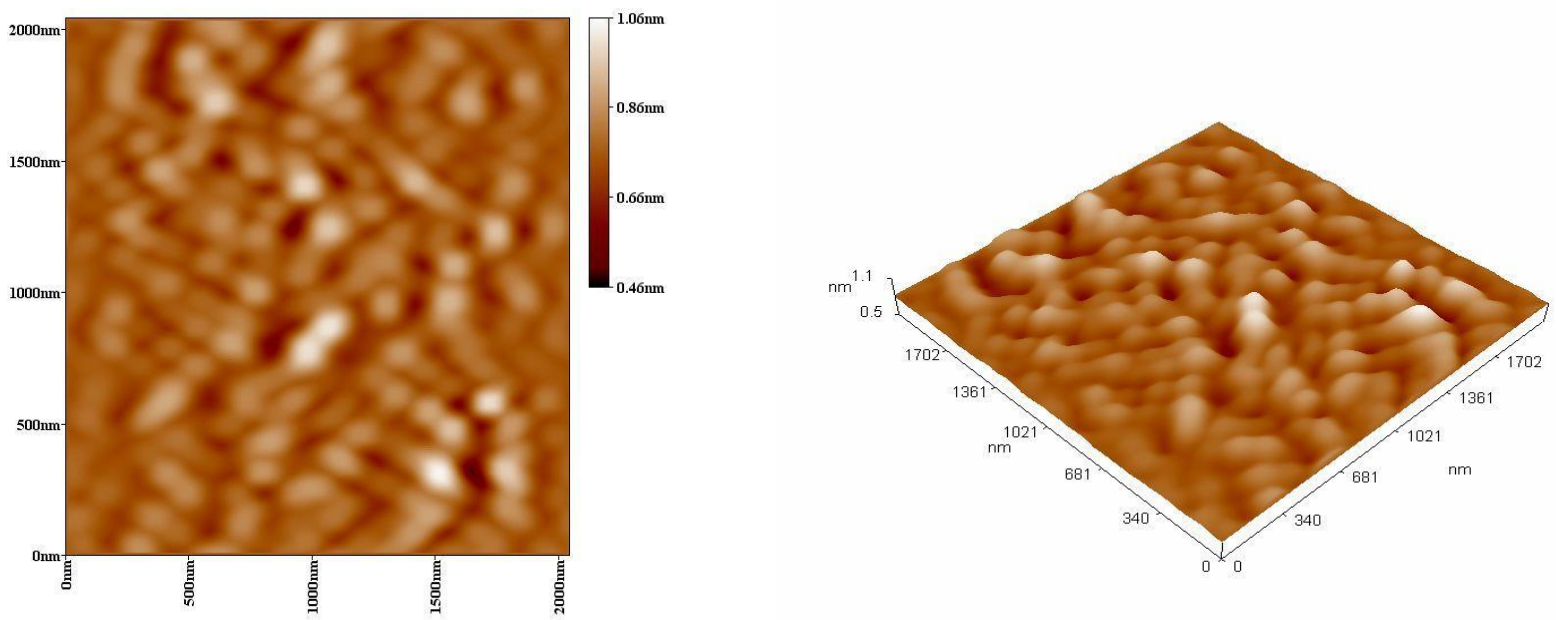

Fig. ( ') CSPM Imager Surface Roughness Analysis of gravel particles GPI.
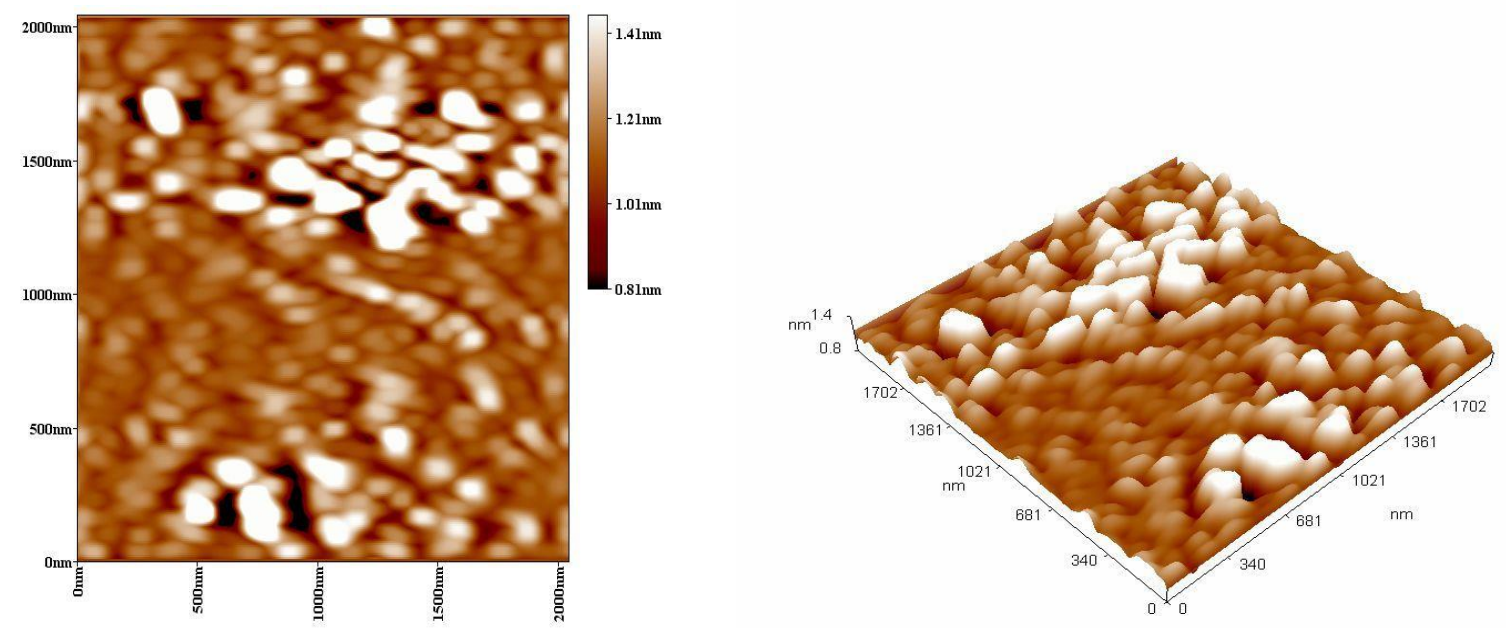

Fig. (") CSPM Imager Surface Roughness Analysis of gravel particles GPII.

\section{(B) Cast Mould}

The cast mould used for casting the polymeric specimens and composites

1. Glass plates of dimensions $(\varepsilon \cdots \mathrm{mm}$ $\times\{\cdots \mathrm{mm} \times \mathbf{\mathrm { mm }}$ ) were used as a mould stages.

$r$. Glass strips of dimensions $(r \cdots \mathrm{mm} \times$ $\left.r \cdot \mathrm{mm} \times{ }^{\top} \mathrm{mm}\right)$ were used as boundaries for the cast mould.

Before casting, a glass plates were cleaned with water and soap solution, after drying in oven, one base of the glass plates was coated with wax, then glass strips were fixed on glass plates and left for one hours to dry at room temperature.

\section{(C) Composites Preparation}

The composites were prepared from unsaturated polyester resin (as a matrix) and the two different types of gravel particles (as a particles fillers) with different weight percentages of $(\mathcal{l} \cdot, r \cdot r \cdot$ and $\varepsilon \cdot) \%$ by molding method which can be summarized by the following steps:

1. Determine the weight gravel particles by using a sensitive balance (four digits).

$r$. Determine the weight of resin and its hardener and mix them carefully.

r. Mix the content thoroughly in a clean disposable container by a fan type stirrer before casting it as sheets (of dimensions r.. $\mathrm{mm} \times 10 . \mathrm{mm} \times 1 \mathrm{~mm})$ by using glass mould. 
$\varepsilon$. Left the composite at room temperature about $r \leqslant$ hours and then for post-curing, the sheets were left for $r$ hours in an oven at temperature $7 .{ }^{\circ} \mathrm{C}$.

(D) Bending Test sample cutting

The sheets of the particles composites are cutting into specimens, by using fine saw, pluses from the samples were removed by using the iron rasp, the samples were grinding by using abrasive emery papers of grade $\varepsilon \cdots$.The shape and dimension of the samples

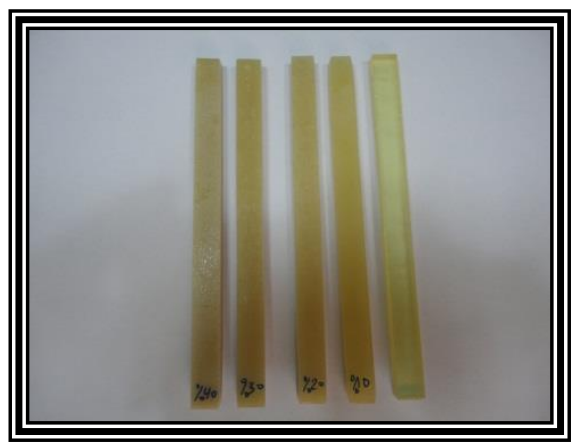

(a) cut for bending test according to [ASTM-

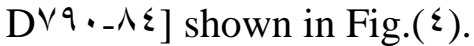

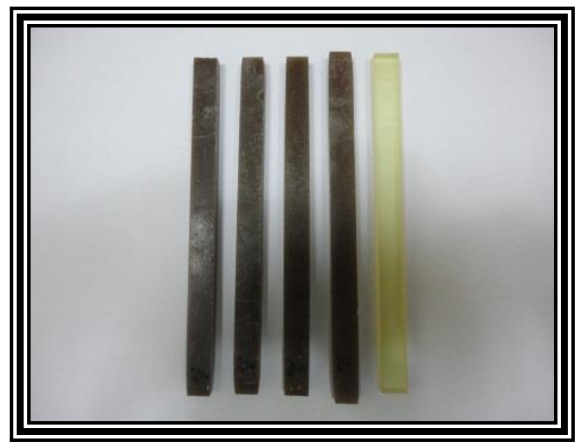

(b)

Fig. ( ) Photograph of bending test specimens before testing. (a) pure polyester and gravel / polyester composites type (I) samples. (b) pure polyester and gravel / polyester composites type (II) samples.

\section{Three - Point Bending Test}

Bending tests were carried out by using an Instron universal testing machine of $\left({ }^{\circ} \mathrm{KN}\right)$ full scale load capacity, according to ASTM standard (D- $\vee q \cdot)$, this test method covers the determination of flexural properties of un reinforced and reinforced plastics in the form of rectangular bars molded directly or cut from sheets, plates or molded shapes. In this method the bar tests on two supports and is loaded by means of a loading nose midway between the supports [11].

\section{Water Immersion}

The test samples of polyester resin and its composites were immersed in hydrant water for ( $r$. days), the immersion test was performed under ambient temperature. The samples removed from water every $r \leqslant$ hours and weighted by using sensitive balance (type: Sartorius, $\mathrm{H}^{01}$ ) of accuracy $1^{1} .^{-\varepsilon}$ gm. For every measurement, the specimens were wiped to remove surface condensation. In addition, the weighting process was carried out in a very short time period to minimize the effects of discontinuity in the moisture absorption process.

\section{Results and Discussion}

\section{(A) Flexural Stress of UPE Resin in Normal Condition (N.C).}

Flexural strength is a measure of the resistance of material to be bent, when it goes under bending moment. During bending, the material undergoes gross flexural deformation before fracture, because the material is exposed to three types of stresses.

The convex side of the material is extended (in Tension mode); while the concave side is compressed (in compression mode) and at the same time, the internal layers of the material shear each other $[1 Y, 1 T]$.

According to the results, Fig. ( $\left.{ }^{\circ}\right)$ shows the flexural stress - strain curve for UPE resin. In UPE system, the cross-linking between the backbone chain restricts the movement of these chains under bending stresses, this will increasing the flexure strength and flexure modulus, and the polymer become brittle [ $1 \leqslant]$. Optical photograph, Fig. ( $\left.{ }^{7}\right)$ shows the fracture region of polyester resin specimen. 


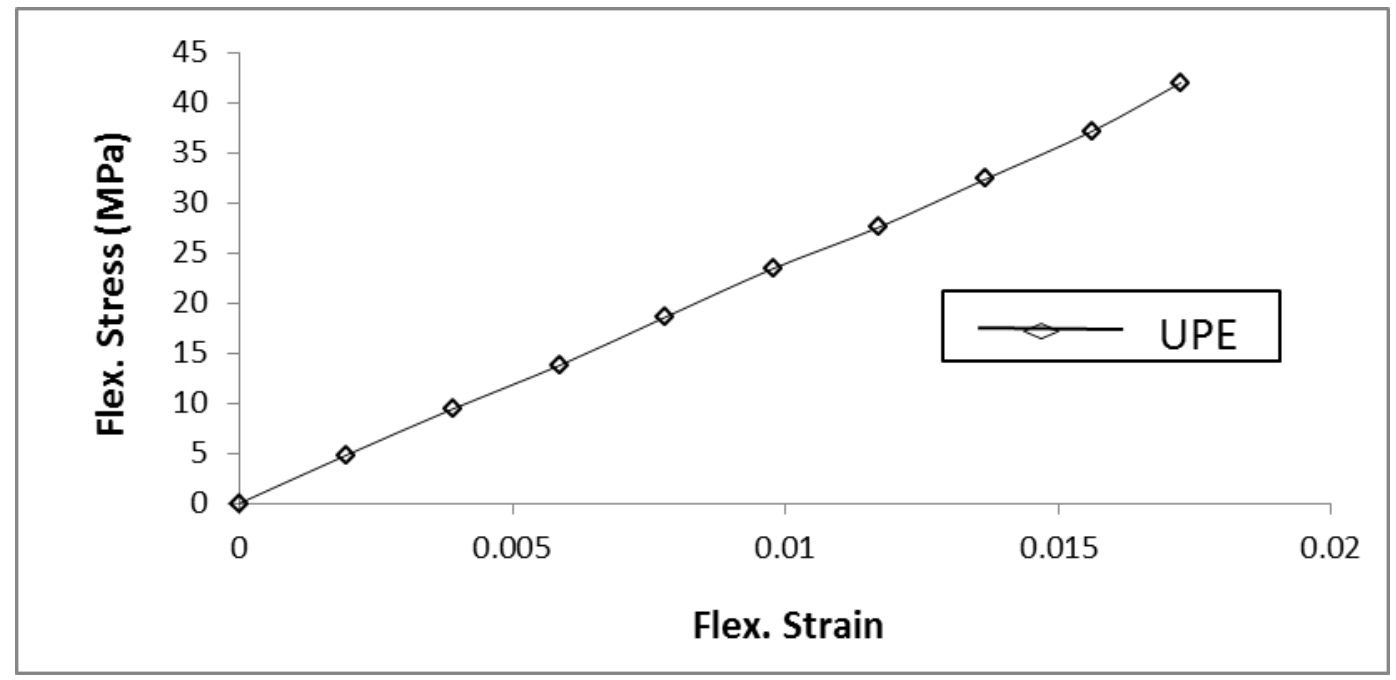

Fig. (๑) Flexural Stress-Flexural Strain curve for UPE.

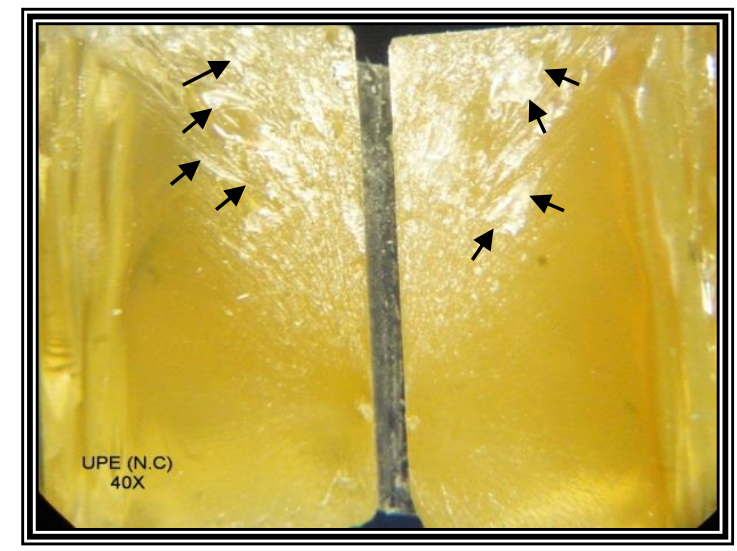

Fig. ( () Photographic images show the fracture region of polyester resin specimen.

\section{B) Flexural Strength of Composites in Normal Condition (N.C).}

From the obtained results the behavior of curves shows different characteristics according to the filling material and its properties (weight percentage, particles size, shape, density, etc.). During the flexural test for composites, there are three factors dominate the resulting flexural strength of a specimen; the flexural strength of the matrix, the adhesion between fillers and matrix and the adhesion between the shape and the characterization of filling materials. This means that, the last two factors are effect on the original strength of the matrix, and these two factors would lead to distribute the applied force on the cross-sectional area of the composite under test.

According to the results shown in Table ( $r$ ) and Fig. $(\checkmark)$, the flexural strength of
(UPE) is increased when it's mixed with gravel particles type II GPII and gained highest values of flexural Strength $(11 \cdot, 9 \mathrm{MPa}$ ) at ratio percent $(r \cdot \%)$. This behaviour in composites is due to high interfacial strength (adhesion), where almost the interactions of polyester with the particles are very strong. Also particles size decreases the space distance between polyester chains which lead to decreasing of bad bonding between polyester chains, these reasons lead to increase of flexural strength of UPE/ GPII composites. In the same Table, it is shown that the samples of UPE \GPII composite have a lower value of flexural strength with increasing the weight percentage of GPII. Optical photograph, Fig. $\left({ }^{\wedge}\right)$ shows the homogeneity between fillers and polymer (UPE), so the fracture surface indicate the debonding of filler during fracture (very rough surface). That means the crack 
propagate through the interface of the matrix/ filler $\left[{ }^{0}\right]$. Also the results show that the UPE/GNPI decrease in the value of flexural strength for all the samples comparing with UPE pure and gained lower values of flexural strength $(r \wedge, r \mathrm{MPa})$ at ratio percent $(r \cdot \%)$, as shown in the Table ( $r$ ) and Fig. ( $\left.{ }^{9}\right)$. In Table ( $r$ ), flexural strength of UPE / GPI composites changing in random form with increasing of the weight percentage of gravel particles and gained highest value of flexure strength $(r \wedge, \odot \mathrm{MPa})$ at ratio percentage $(r, \%)$. The addition of GPI to UPE resin acts to decrease the flexural strength of composites. This obtained result may be attributed to the poor adhesion at the filler/matrix interface. In addition, the interfaces between particles and matrix will be under stresses, so many micro cracks will appear and the stress concentration on the ends of these micro cracks will increase, so that the crack will spread and fracture occur. That means the addition of powder filler to the polymer matrix lead to decrease in stress. This can be explained via returning to the different mechanisms, which depends on the bonding type between the particles and the matrix. The mechanism; represent the weak bonding case between the two phases of composite, and this behavior agrees with that obtained by Nicolai's [17]. Fig. (1.) shows photographic image for fracture regions of GPI samples.

Table ( r)

Values of Flexure Stress for UPE and (UPE/GPI, UPE/GPII) composites

\begin{tabular}{|c|c|c|c|c|}
\hline \multirow[t]{2}{*}{ Composition } & \multicolumn{4}{|c|}{$\begin{array}{c}\text { Flexure Stress F.S (MPa) } \\
\text { Gravel particles content } \\
(\text { wt. \%) }\end{array}$} \\
\hline & $1 . \%$ & $r . \%$ & $r . \%$ & $\varepsilon . \%$ \\
\hline $\begin{array}{c}\text { UPE/GPI } \\
\text { (N.C) } \\
\end{array}$ & $r v, r$ & $r \wedge, r$ & $r \Lambda, 0$ & r \\
\hline $\begin{array}{c}\text { UPE/GPII } \\
\text { (N.C) }\end{array}$ & $1 \cdot \varepsilon$ & $11 \cdot, 9$ & $\Lambda 0, Y$ & $\Delta r, r$ \\
\hline
\end{tabular}

F.S $S_{U P E(N . C)}=\leq M M P a$.

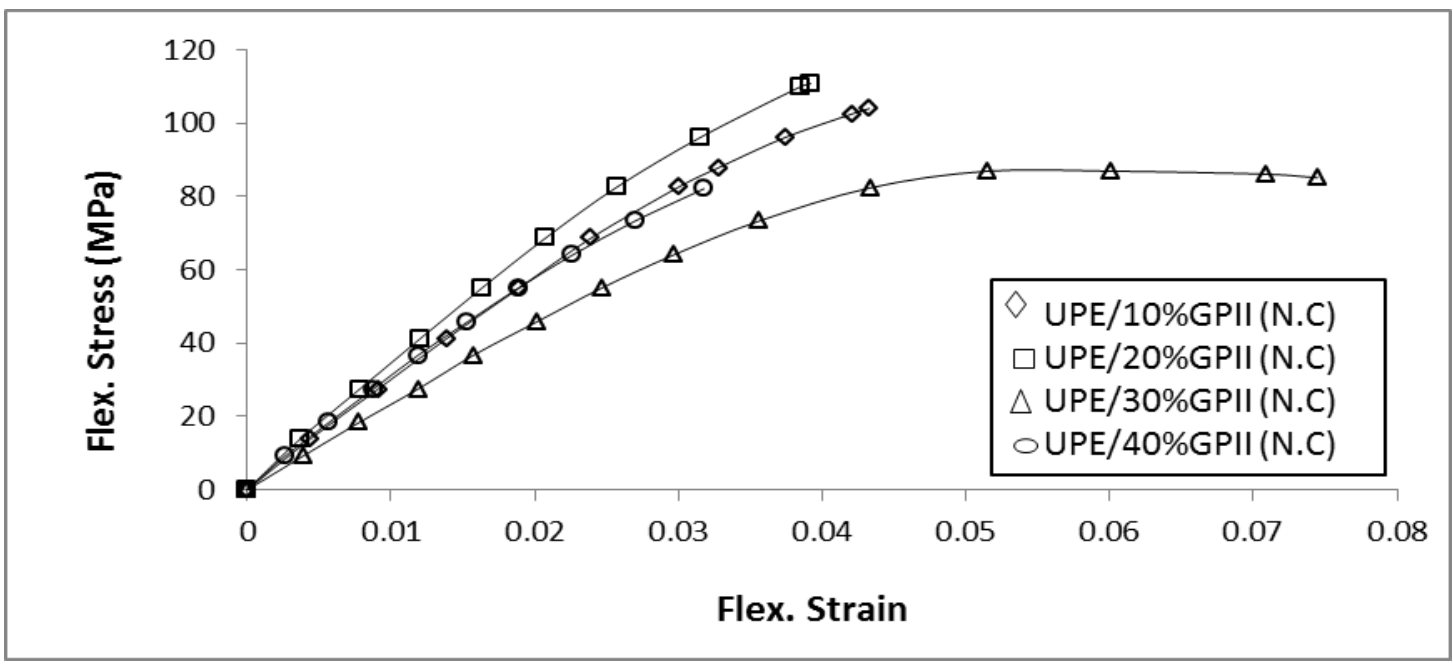

Fig. ( V) Flexural Stress-Flexural Strain curve for GPII (N.C) composites.

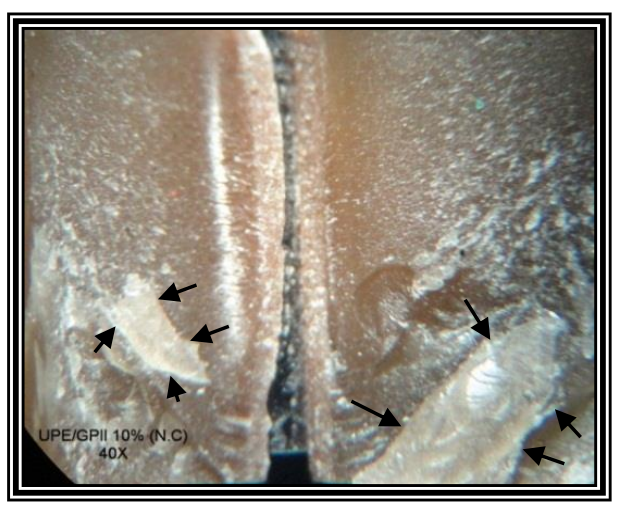

(a)

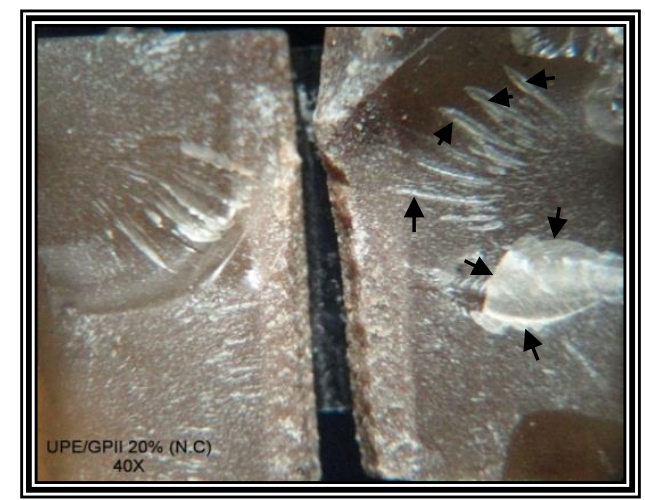

(b) 


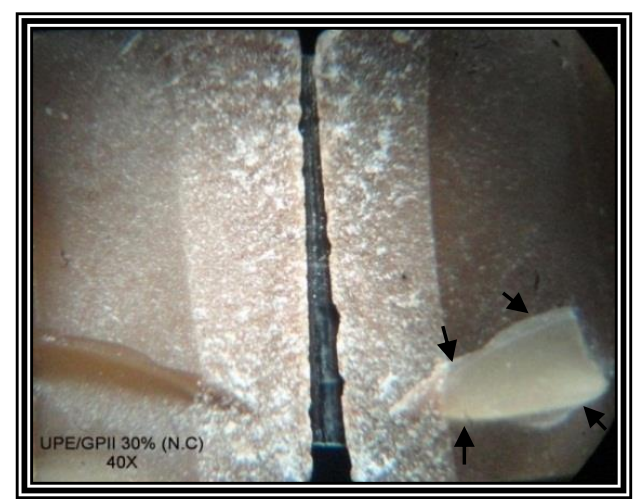

(c)

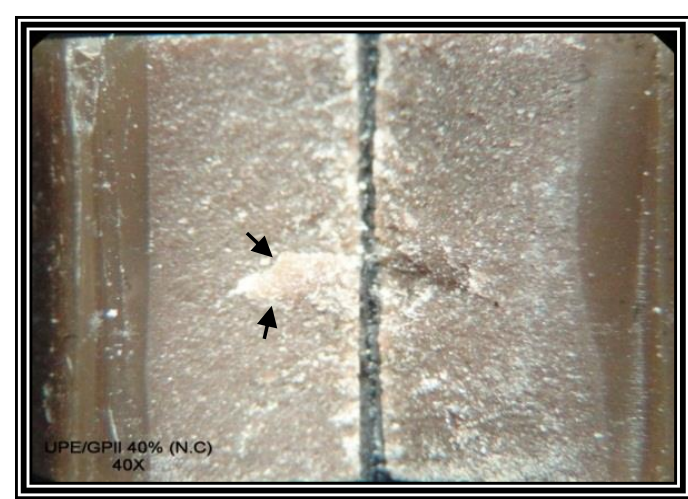

(d)

Fig. ( 1) Optical photographs show:

(a) The fracture regions of UPE/ 1 . \%PII composite specimen (N.C).

(b) The fracture regions of UPE/ $\uparrow . \%$ GPII composite specimen (N.C).

(c) The fracture regions of UPE/ $/ \%$ GPII composite specimen (N.C).

(d) The fracture regions of UPE/ $₹$ * GPII composite specimen (N.C).

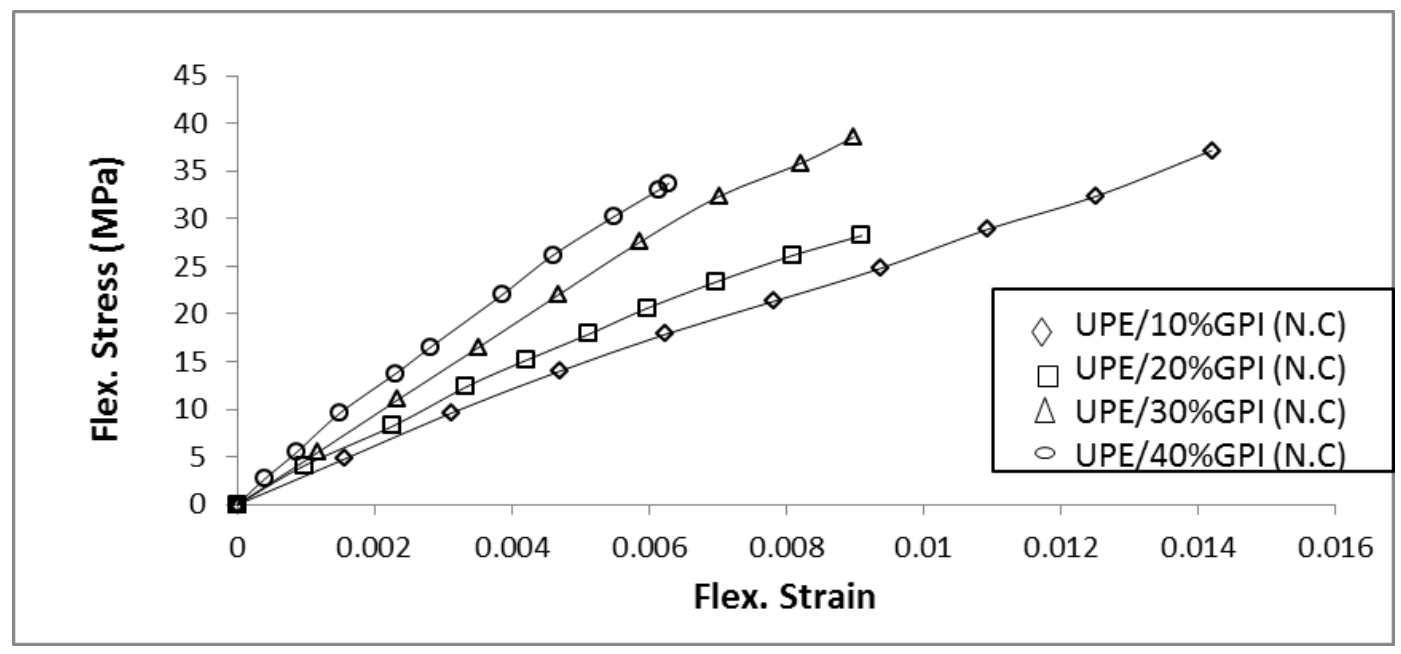

Fig. ( () Flexural Stress-Flexural Strain curve for GPI (N.C) composites.

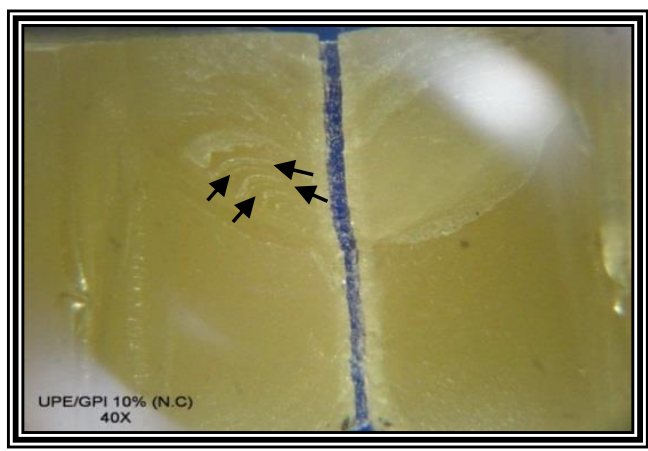

(a)

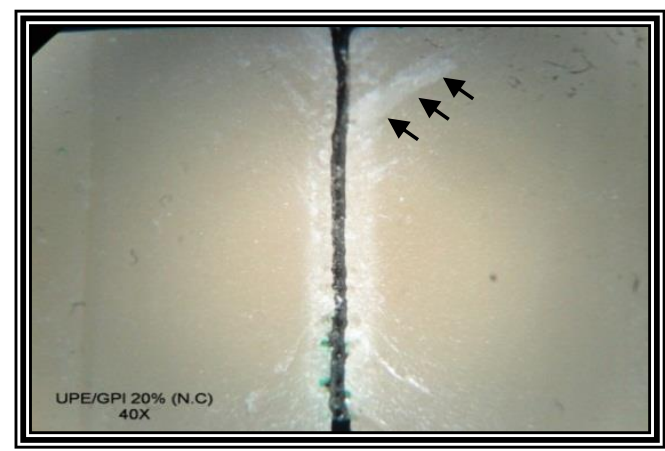

(b) 


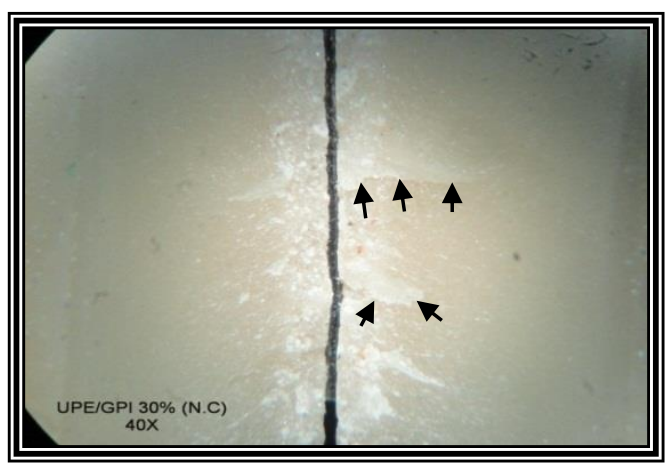

(c)

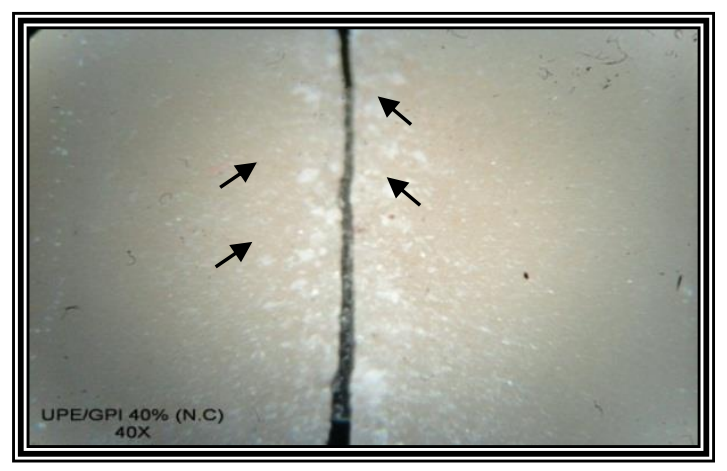

(d)

Fig. ( 1.$)$ Optical photographs show:

(a) The fracture regions of UPE/ 1 \% GPI composite specimen (N.C).

(b) The fracture regions of UPE/ $+\%$ GPI composite specimen (N.C).

(c) The fracture regions of UPE/ $\%$ \%PI composite specimen (N.C).

(d) The fracture regions of UPE/ $\div$ \%GPI composite specimen (N.C).

C) Young's modulus of Composites in Normal Condition (N.C).

The Young's modulus (E) is a measure of stiffness (rigidity) of the material. The greater the Young's modulus, the smaller the elastic strain resulting from the application of a given stress [ $\mathrm{IV}]$.

Table ( $\left.{ }^{r}\right)$ states that the Young's modulus (E) of UPE has been increased after blending with GPI and GPII except percent $r . \%$ of UPE/GPII composites it shows that at this percentage the value of Young modulus (E) of the specimen is lower than other percentages compared with UPE pure. The reason for this increasing is the decreasing in the flexibility of the polymer chains for the composites compared with that of pure (UPE). This implies raise in the stiffness (rigidity), which means, these composites will have new prospect of application. The results of Young modulus (E) of UPE/GPI composites in Table ( $($ ) show an increase of Young modulus with increasing the GPI weight percentages; this behaviour is due to existence GPI in polyester matrix causing an increase of the immobility of polyester chains. The mechanism of increase of Young modulus in the existence of particles is increased immobility of polyester chains in existence of GPI act as rigid particles that obstruct polyester chains mobility. The results of Young modulus (E) of UPE/ GPII composites in Table $(r)$ show an increase of Young modulus in random form with increasing the gravel particles weight percentage and gained highest value $(r, 0 \wedge \mathrm{GPa})$ at weight percentage $(r \cdot \%)$.

Table (

Values of Young modulus for UPE and (UPE/GPI, UPE/GPII) composites.

\begin{tabular}{|c|c|c|c|c|}
\hline \multirow{3}{*}{ Composition } & \multirow{2}{*}{\multicolumn{4}{|c|}{$\begin{array}{c}\text { Young's Modulus (GPa) } \\
\text { Gravel particles content } \\
(w t . \%)\end{array}$}} \\
\hline & & & & \\
\hline & $1 . \%$ & $r . \%$ & $r . \%$ & $\varepsilon . \%$ \\
\hline $\begin{array}{l}\text { UPE/GPI } \\
\text { (N.C) }\end{array}$ & $\mu$ & $\Gamma, \wedge \varepsilon$ & $\varepsilon, 79$ & $7, \leqslant 9$ \\
\hline $\begin{array}{l}\text { UPE/GPII } \\
\text { (N.C) }\end{array}$ & $r, 1$ & $\Gamma, 0 \wedge$ & o & $r, r q$ \\
\hline
\end{tabular}

$\mathbf{E}_{\mathrm{UPE}(\mathrm{N} . \mathrm{C})}=\mathrm{Y}, \varepsilon \mathbf{G P a}$

\section{D) Effect of water of UPE Resin and its composites}

The UPE and UPE/GPI, UPE/ GPII composites samples were immersed in water about ( $r \cdot$ days) to find the effect of water on their flexural strength and Young's Modulus. The results of these tests are shown in Figs. ( 11 ) to (1 $)$. The reason behind this test is that water causes degradation in the properties of most composite material with polymeric matrices $[1 \wedge]$.

The results in Table ( $\varepsilon$ ) and Figs. ( 11 and $1 r$ ) showed an increase in values of flexural strength for UPE/GPI samples at weight percentage $(1 \%)$ compared with UPE pure 
Journal of Al-Nahrain University

\section{Science}

after immersion and the results of flexural strength of UPE/GPI composites show a slight decrease with increase the gravel particles weight percentage and gained highest value $(\leqslant \vee, \uparrow \mathrm{MPa})$ at weight percentage $(1 . \%)$ after immersion. Fig.( $(\leqslant)$ Optical photographs show the fracture regions of UPE/GPI composites.

From the same Table and Figs. ( 11 and $1 T$ ), it can be seen, that the flexural strength for UPE/GPII samples increased at weight percentage $(1 . \%)$ compared with UPE pure matrices and the results of flexural strength of UPE/GPII composites clear a slight decrease with increase the gravel particles weight percentage and gained highest value $(\varepsilon \cdot, \uparrow \mathrm{MPa})$ at weight percentage $(1 \cdot \%)$. Fig. $(10)$ Optical photographs show the fracture regions of UPE/GPII composites.

\section{Table ( $\varepsilon)$}

Values of Flexure Stress for UPE and

(UPE/GPI, UPE/GPII) composites after immersion (A.I).

\begin{tabular}{|c|c|c|c|c|}
\hline \multirow{3}{*}{ Composition } & \multirow{2}{*}{\multicolumn{4}{|c|}{$\begin{array}{c}\text { Flexure Stress F.S (MPa) } \\
\text { Gravel particles content } \\
(w t . \%)\end{array}$}} \\
\hline & & & & \\
\hline & $1 . \%$ & $F . \%$ & $\mu \cdot \%$ & $\varepsilon \cdot \%$ \\
\hline $\begin{array}{c}\text { UPE/GPI } \\
\text { (A.I) }\end{array}$ & $\varepsilon V, 7$ & $r \wedge, 0$ & ro, & $r q, 7$ \\
\hline
\end{tabular}

Vol. IV (\&), December, r. Is, pp. $\left|10_{-}\right| r V$

\begin{tabular}{|c|c||c||c||c|}
\hline $\begin{array}{c}\text { UPE/GPII } \\
\text { (A.I) }\end{array}$ & $\varepsilon \cdot, \tau$ & $r q, \tau$ & $r_{\cdot}, \tau$ & $19, r$ \\
\hline
\end{tabular}

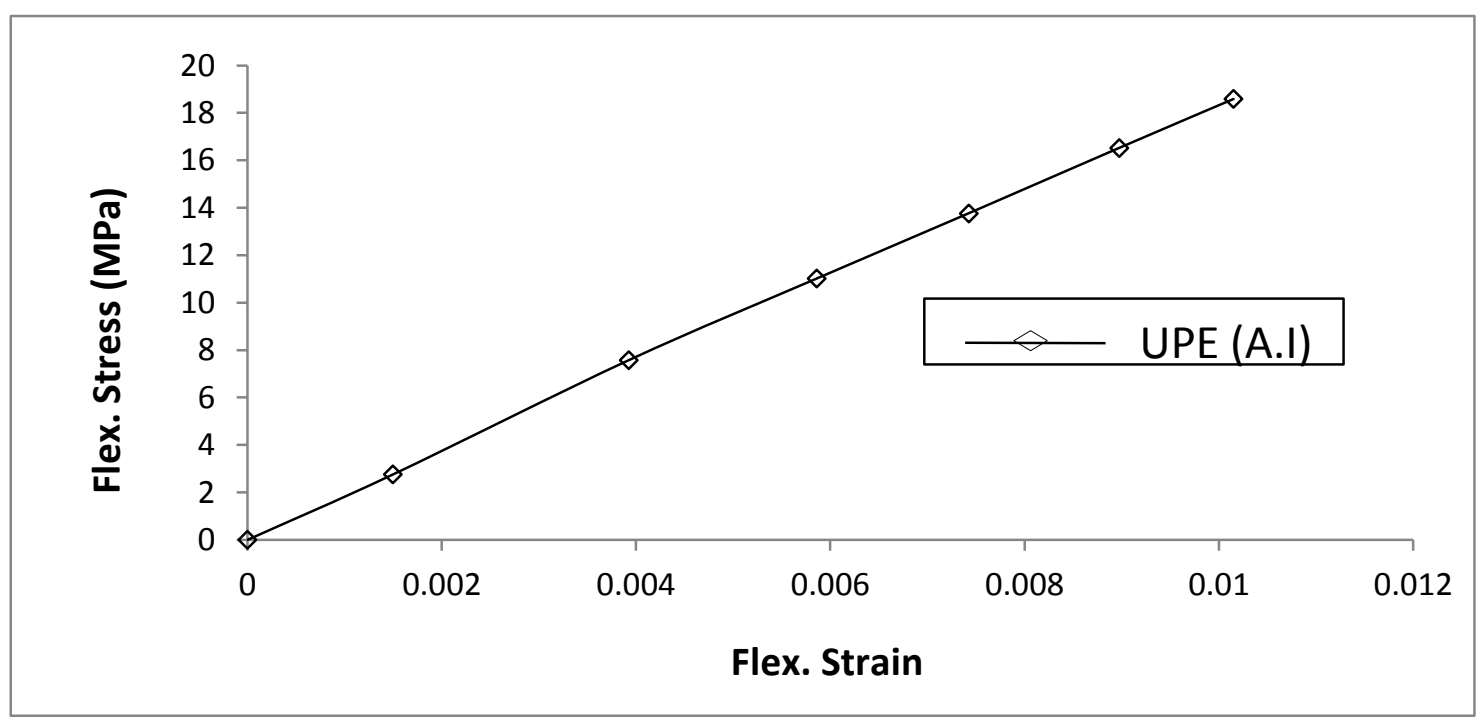

Fig. (' ') Flexural Stress-Flexural Strain curve for UPE after immersion (A.I). 


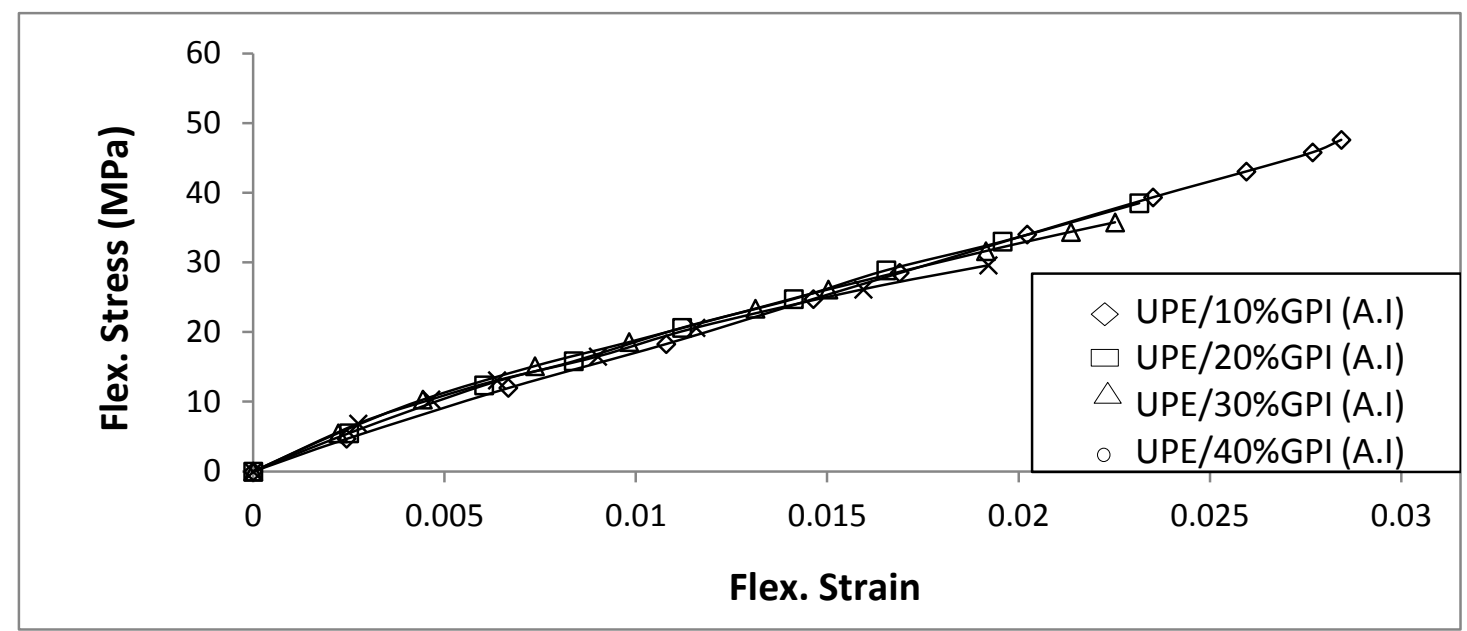

Fig. ( 1 ') Flexural Stress -Flexural Strain curve for GPI composites after immersion (A.I).

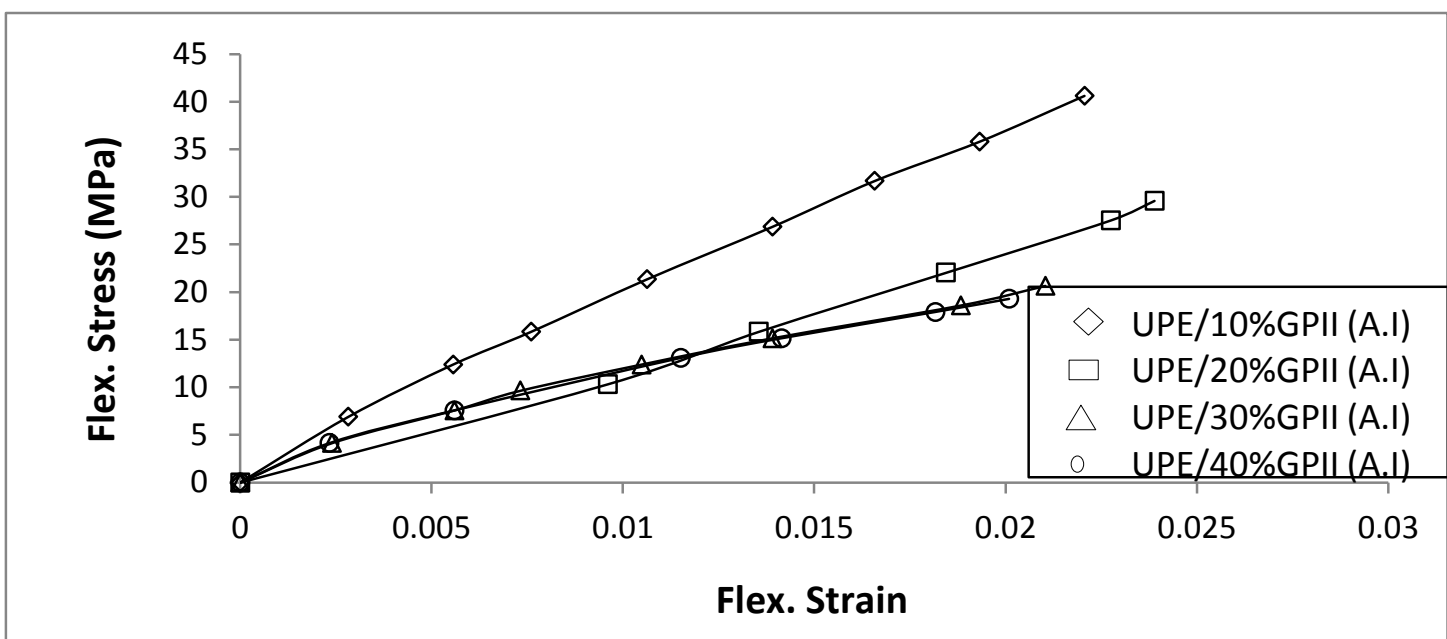

Fig. ( 1 m) Flexural Stress -Flexural Strain curve for GPII composites after immersion (A.I).

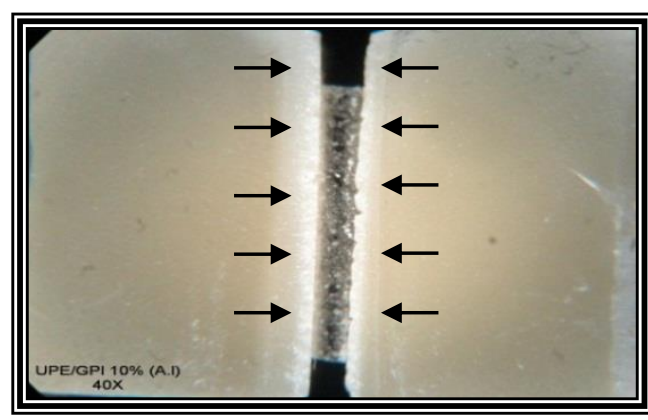

(a)

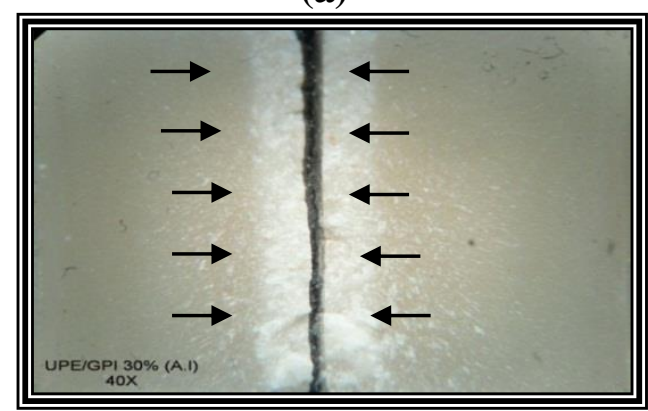

(c)

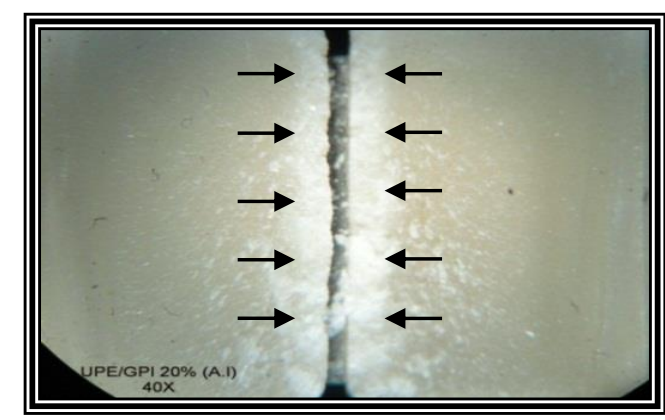

(b)

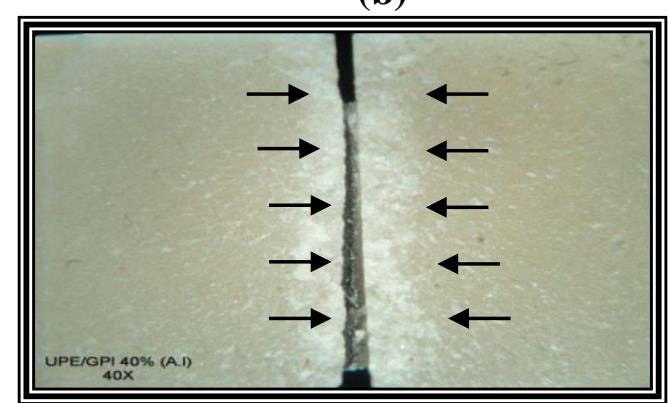

(d)

Fig. ( 1 \&) Optical photographs show:

(a) The fracture regions of UPE/ $1 \%$ GPI composite specimen (A.I). 
(b) The fracture regions of UPE/ $\mathrm{F} \%$ GPI composite specimen (A.I).

(c) The fracture regions of UPE/ $\%$ \% GPI composite specimen (A.I).

(d) The fracture regions of UPE/ $\leftleftarrows \%$ GPI composite specimen (A.I).

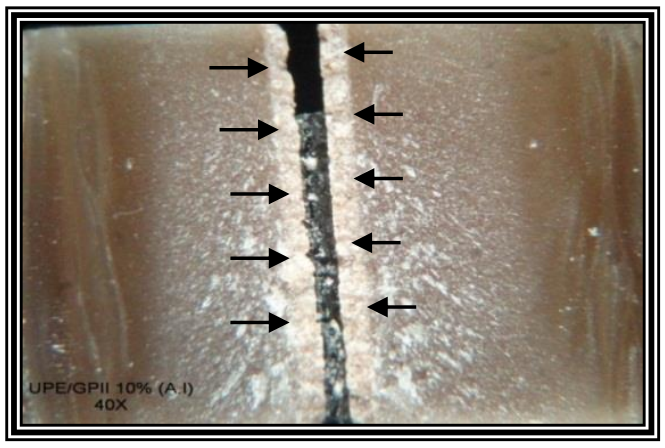

(a)

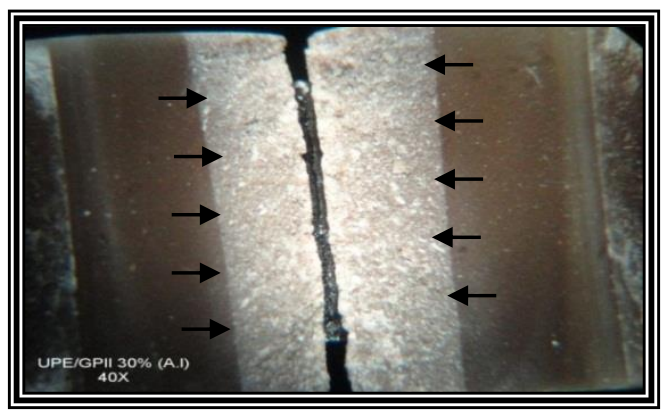

(c)

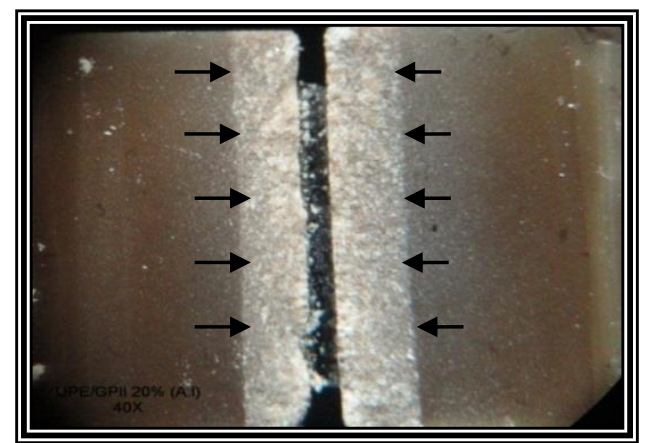

(b)

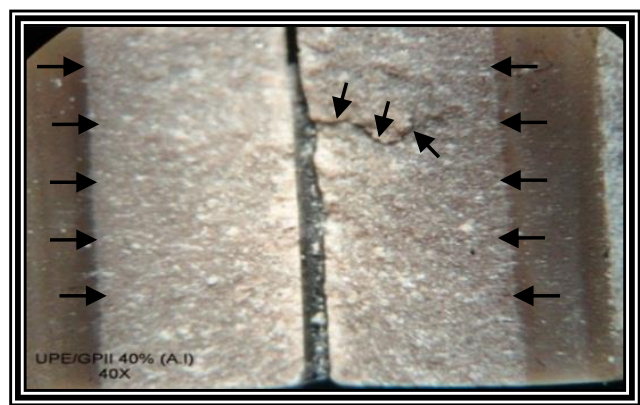

(d)

Fig. ( 10$)$ Optical photographs show:

(a) The fracture regions of UPE/ $1 \%$ GPII composite specimen (A.I).

(b) The fracture regions of UPE/ $\uparrow \%$ GPII composite specimen (A.I).

(c) The fracture regions of UPE/ $\%$ \% GPII composite specimen (A.I).

(d) The fracture regions of UPE/ $\leftleftarrows \%$ GPII composite specimen (A.I).

Table $\left({ }^{\circ}\right)$ shows a slight changing in values of Young's Modulus (E) after immersion between increase and decrease for all the samples compared with UPE pure and gain highest value of young modulus $(r, r \wedge \mathrm{GPa})$ at weight percentage $r . \%$ for UPE/GPI composites, Also the results show that the UPE/ GPII gain highest value of young modulus (E) $(r, r \circ \mathrm{GPa})$ at weight percentage $1 . \%$. This reduction in the values of Young's Modulus (E) of samples being subjected to water was due to the plasticization effect and reduced interfacial adhesion between the fillers and the matrix. Many of the polymers used in composites; (including UPE) take some percentages of water if they are immersed in it for some time. This would swell and plasticize them, causing a reduction in $(\mathrm{E})[19]$.
Table ( $\bullet$ )

Values of Young modulus for UPE and (UPE/GPI, UPE/GPII) composites after immersion (A.I).

\begin{tabular}{|c|c|c|c|c|}
\hline \multirow{3}{*}{ Composition } & \multirow{2}{*}{\multicolumn{4}{|c|}{$\begin{array}{c}\text { Young's Modulus E (GPa) } \\
\text { Gravel particles content } \\
(w t . \%)\end{array}$}} \\
\hline & & & & \\
\hline & $1 . \%$ & $r \cdot \%$ & $\mu \cdot \%$ & $\varepsilon . \%$ \\
\hline $\begin{array}{l}\text { UPE/GPI } \\
\text { (A.I) }\end{array}$ & 1,1 & r & $r, Y \wedge$ & $r, Y_{T}$ \\
\hline $\begin{array}{l}\text { UPE/GPII } \\
\text { (A.I) }\end{array}$ & $r, r_{0}$ & 1,10 & $1, \leqslant 7$ & $1, \leqslant r$ \\
\hline
\end{tabular}

$\boldsymbol{E}_{U P E(N . C)}=1,1 \wedge G P a$

\section{Conclusion}

This experimental investigation of mechanical behaviour of gravels particles as 
a fillers filled polyester composites leads to the following conclusions:

- The polyester resin is a good adhesive material which can use as a matrix with Gravel particles.

- We can produce a composite hard, strong by use small particle size of Gravel as fillers.

- The results of flexural strength for UPE/GPII composites are greater than UPE/GPI composites at the same weight percentage in normal condition.

- Prepare material composite important in industrial applications such as waste water pipes.

- The results of flexural strength for UPE/GPII composites are greater than UPE/GPI composites with the same filler weight percentage.

\section{References}

[1] Miroslav Muller, "Polymeric Composites Based on ALrOr Reinforcing Particles" Engineering for Rual Development, Jelgava, Y. Il.

[r] Saad M. Elia, "Study the effect of Adding sea nodules powers on Flexural Strength and Hardness of Unsaturated polyester Resin", Eng. \& Tech. Journal, vol. ${ }^{q}$, No. ${ }^{r}, r \cdot 11$.

[r]Gang Sui, Soumen Jana, Amin SalehiKhojin, Saujay Neema, Wei-Hong Zhong, Huichen and OunHuo," Preparation and properties of Natural Sand Particles Reinforced Epoxy Composites", Macromolecular Materials and Engineering Journals, $\left(\left\{\tau V_{-} \leqslant \vee T\right)\right.$, $r \ldots v$.

[₹] Wikipedia, the free encyclopedia, "Aggregate (composite)", This page was last modified on $r$ February $r \cdot 1 r$.

[0] Ahmed Jdah F. "Investigation of Some Mechanical Properties of Sawdust and Chopped Reeds/ UPE Composites". M.Sc. Thesis. Department of physics. University of Baghdad Y. 11.

[ฯ] Young R.J. \& Beaumont P.W.R.,"Failure of Brittle polymers by slow crack Growth parts: effect of composite up on the fracture of silica particle-filled Epoxy Resin Composite", Journal of Material science,

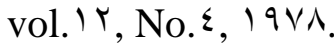

[V] بلقيس محمد ضياء، عدنان رعد احمد، خالد حمدي

رزيج "دراسة خاصيتي الصدمة والصلادة لمواد متراكبة

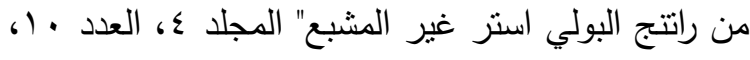

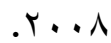

[^] Sewench N. Rafiq and Najlaa Rouchdy, "effect of filler particle size and concentration on the Mechanical and thermal properties of polymer composite", Taqani Journal, vol. rr,No. l, r. ${ }^{\top} \cdot$.

[9] Hanaa A.S. "Effect of Reinforced by Zinc oxide powder on the mechanical properties for unsaturated polyester matrix composite material", Journal of Eng. \& Tech., vol. ${ }^{\Upsilon}$, No. $1 \cdot, \cdot, 11$.

[l·] Wassan J. M. "Studying the physical behavioure for a particulated polymeric composite material", M.S.C Thesis, Department of applied sciences, University of Technology, r...o.

[1'] Annual Book of ASTM Standareds, ^ (1), $19 \wedge \varepsilon$.

[IY] Chawla K.K., Composite Materials (Science and Engineering), SpringerVerlag New York Inc, 19^V.

[1T] James M. G., "Mechanics of Materials", sixth edition, Thomson, Canada,,$\ldots \varepsilon$.

[ $\left.{ }^{\prime}\right]$ H. I. Jaffer "Ph. D Thesis "Physics Dep. College of Science, University of Baghdad,, ....

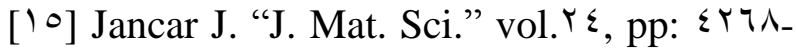
$\varepsilon r \vee \leqslant, 19 \wedge 9$

[17] Nicolais L., Guerra G., Migliaresi C., Nicodemo L. and Benedetto A. T. "Composites" vol. I $\mathrm{N}$. \& January 1911.

[lv] Agrawal B.K., "Introduction to Engineering Materials", \& th edition, Tota Mc Grew-Hill Publishing Company Limited, New Delhi, 199 ร.

[1^] Dewimille B. \& Bunsell A.,

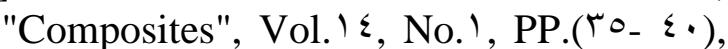
$19 \wedge r$

[19] Wright W.W., "Composites", Vol. Ir, No.r.PP. $(r \cdot 1-r \cdot 0), 1911$. 


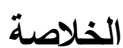

نظرا للنطورات في التطبيقات الصناعية التي حصلت في

السنوات الأخيرة والحاجة الى استخدام المواد المتراكبة بشكل عام والمتراكبة البوليمرية بشكل خاص في مختلف التطبيقات

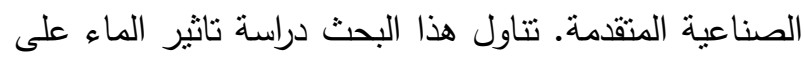

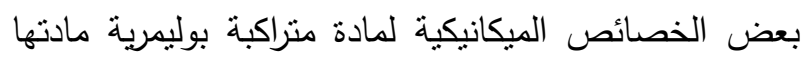
الاساس (بولي استر غير مشبع) مدعم بنوعين مختلفين من

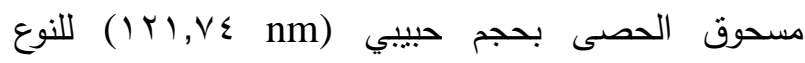

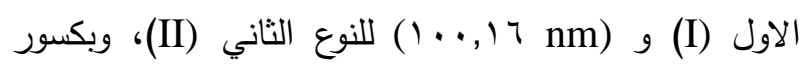

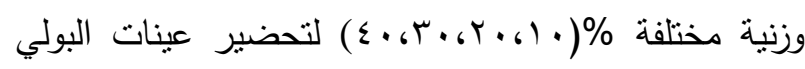
استر • استخدمت طريقة القولبة اليدوية في تحضير عينات البولي استر النقي، عينات منراكب البولي استر/ دقائق

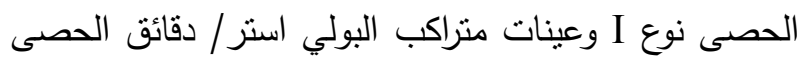
نوع الخاصة لاختبار الثني عند الظروف الطبيعية وتم دراسة خواصها الميكانيكية التي تتضمن معامل يونك ومتانة

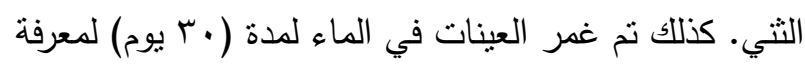
تأثثر الماء على متانة الثني ومعامل يونلك. بينت النتائج

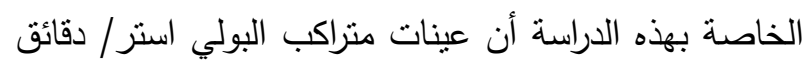

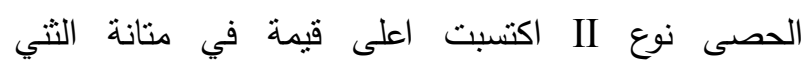

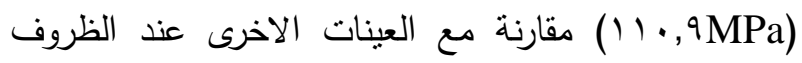

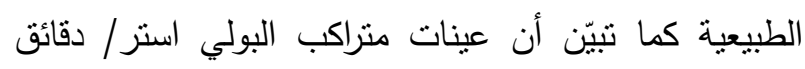

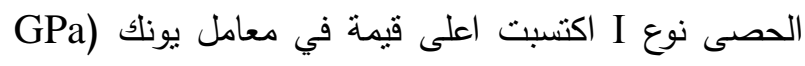
9 § , ؟) مقارنة مع العينات الاخرى عند الظروف الطبيعية.

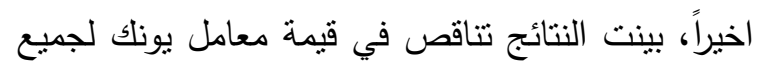

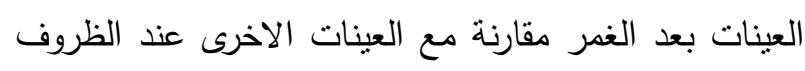

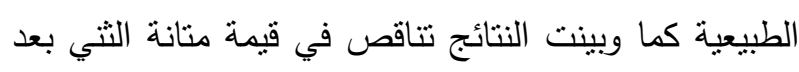

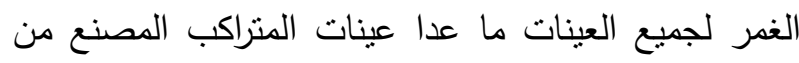

